\title{
Numerical simulation of centrifuge tests on homogeneous and heterogeneous soil models
}

\author{
Pradipta Chakrabortty ${ }^{\mathrm{a}, *}$, Radu Popescu ${ }^{\mathrm{b}}$ \\ a Faculty of Engineering and Applied Science, Memorial University of Newfoundland, St. John's, NL, Canada A1B3X5 \\ ${ }^{\mathrm{b}}$ URS Corporation, 510 Carnegie Center, Princeton, NJ 08540, USA
}

Keywords:

Spatial variability

Finite element analysis

Seismic induced liquefaction

Centrifuge tests

\begin{abstract}
A B S T R A C T
Soil liquefaction is a major cause of seismic damage in cohessionless soil during earthquakes. From past numerical and experimental research it has been observed that more excess pore water pressure (EPWP) is generated during earthquakes in a heterogeneous soil deposit than in the corresponding homogeneous soil with relative density equal to the average relative density of the heterogeneous soil. This interesting phenomenon is investigated here, by numerically simulating centrifuge experiments of seismically induced soil liquefaction using the finite element code DYNAFLOW. Two centrifuge tests are numerically simulated here: one in homogeneous soil and another in heterogeneous soil. Recorded experimental results such as accelerations, EPWP and settlements are compared with the simulated numerical results. Numerically simulated and recorded results support the conclusions of previous research that more EPWP is generated in a heterogeneous soil deposits than in the corresponding homogeneous soil.
\end{abstract}

\section{Introduction}

Soil liquefaction is a major cause of concern in cohessionless soil during earthquakes. After the devastating earthquakes at Alaska and Niigata in 1964, this phenomenon has received a lot of attention in the last few decades. Different methodologies have been proposed to estimate and understand the consequences of seismically-induced liquefaction on the performance of geotechnical systems. Finite element methodology coupled with physical centrifuge tests is one of the robust methods for understanding the phenomenon and predicting the effects of soil liquefaction. In the last few decades, with the advances in the computer hardware, this has been widely used in soil liquefaction studies. The Verification of Liquefaction Analysis by Centrifuge Studies (VELACS) project [1], sponsored by the National Science Foundation (NSF), was one of the largest research projects in this area, leading to the development of several centrifuge validated numerical procedures for simulating soil liquefaction $[2,17,26]$. Most of the available literature on the numerical simulation of soil liquefaction in centrifuge tests were either with uniform soil or layered soil deposits. For example, a study on mitigation of seismic liquefaction effects, based on centrifuge and numerical modeling, was documented

* Corresponding author. Present address: Department of Civil Engineering, Birla Institute of Technology and Science, Pilani, Rajasthan, India. Tel.: +919785011633 fax: +91 1596244183 .

E-mail addresses: pradipt@gmail.com (P. Chakrabortty), radu@princeton.edu (R. Popescu). by Jafari-Mehrabadi [14]. One of the objectives of that study was to demonstrate the effect of impervious soil layers in a sand slope, leading to considerably lower liquefaction resistance. Ghosh and Madabhushi [11] performed a series of centrifuge experiments to analyze the effects of a localized loose zone in a dense sand deposit subjected to seismic loads. It was found that the effect of the loose sand zone was to induce increased excess pore water pressure (EPWP) in the surrounding dense sand. However, until now, there is no other experimental study available with spatially variable soil (variability in both the horizontal as well as vertical direction).

The main objective of this research is simulating soil liquefaction in heterogeneous soil using a numerical model validated based on centrifuge test results. A series of three geotechnical centrifuge tests were performed at the C-CORE centrifuge facility: one on homogeneous soil and two on heterogeneous soil. The physical test results were already reported by Chakrabortty [5] and Chakrabortty et al. [6,7]. The test on uniform soil was performed on a soil deposit with the soil relative density lower than the average relative density of the heterogeneous soil deposit. Two of these centrifuge tests (Test 1: uniform soil, Test 3: variable soil) are numerically simulated and results are reported in this study. The numerical model is first calibrated from the results obtained from homogeneous soil deposits. Then, that calibrated numerical model is used for simulating the results in heterogeneous soil deposits. Measured experimental results such as accelerations, excess pore water pressures and settlements were compared with the simulated numerical results of the centrifuge tests. In seismically induced soil liquefaction, it has been seen $[5-7,25,28-30]$ that a 
larger amount of excess pore water pressure is generated in a heterogeneous soil than in the corresponding uniform soil having geotechnical properties equal to the average properties of the variable soil. This present study also supports these previous findings.

\section{Numerical modeling}

\subsection{Numerical modeling of seismic induced liquefaction}

In a seismic analysis of saturated soils two important aspects need to be addressed (e.g., [30]): (a) solid and fluid coupled field equations have to be used in a step-by-step (time domain) dynamic analysis to correctly capture the inertial and dissipative coupling terms; and (b) accurate simulation of dynamically induced EPWP build-up and continuous softening of the material requires soil models able to reproduce the experimentally observed nonlinear hysteretic behavior and shear stress-induced anisotropic effects, and to reflect the strong dependency of plastic dilatancy on effective stress ratio. The first aspect is addressed in the DYNAFLOW code by the extension of Biot's theory into the nonlinear regime [30]. Nonlinear dynamic constitutive behavior of saturated soil under partially drained conditions is modeled using a kinematic hardening, multi-yield constitutive model based on a simple plasticity theory [31]. The yield function is described in the principal stress space by a set of nested rounded Mohr-Coulomb yield surfaces. A non-associative plastic flow rule is used for the dilatational component of the plastic deformation. The model has been tailored to retain the extreme versatility and accuracy of the simple multi-surface $\mathrm{J}_{2}$ theory in describing observed shear nonlinear hysteretic behavior and shear stress induced anisotropic effects, and to reflect the strong dependency of the shear induced dilatancy on the effective stress ratio. Accurate simulation of shear-induced plastic dilation and of hysteretic effects under cyclic loading, together with full coupling between solid and fluid equations, allows capturing the build-up and dissipation of pore-water pressures and modeling the gradual softening and hardening of soil materials. The required constitutive model parameters can be derived from the results of conventional laboratory (e.g., triaxial, simple shear) or in situ (e.g., standard penetration, cone penetration, wave velocity) soil tests. The multi-yield plasticity soil constitutive model, its implementation algorithm, and the methodology for estimating the constitutive model parameters have been repeatedly validated in the past for soil liquefaction computations, based on both centrifuge experimental results (e.g., [14,26,27]) and full scale measurements (e.g., [15]).

\subsection{Finite element model}

A simple frame structure was placed on the sand surface in each test. The structure and adjacent soil were analyzed using the plane strain assumption. The synthetic input seismic acceleration time history (shown in Fig. 1) was applied at the base of the centrifuge box. The earthquake time history used in these centrifuge experiments was selected as the $2 \%$ earthquake in 50 years for Vancouver area based on the firm ground target spectrum in NBCC [22]. It was then amplified by 1.46 times to obtain a peak ground acceleration of $0.25 \mathrm{~g}$ and used during centrifuge tests. The input motion used in the centrifuge (as recorded by the acceleration transducer mounted on the centrifuge box) for homogeneous soil model was almost identical with the one recorded in the heterogeneous soil model and is shown in Fig. 1a. The corresponding input motions have been used in the numerical analysis. The response spectra for 5\% damping for both accelerometers are shown in Fig. 1b.

A $20 \mathrm{~m}$ deep, $44 \mathrm{~m}$ long saturated sand deposit corresponding to the prototype scale dimensions of the centrifuge models was
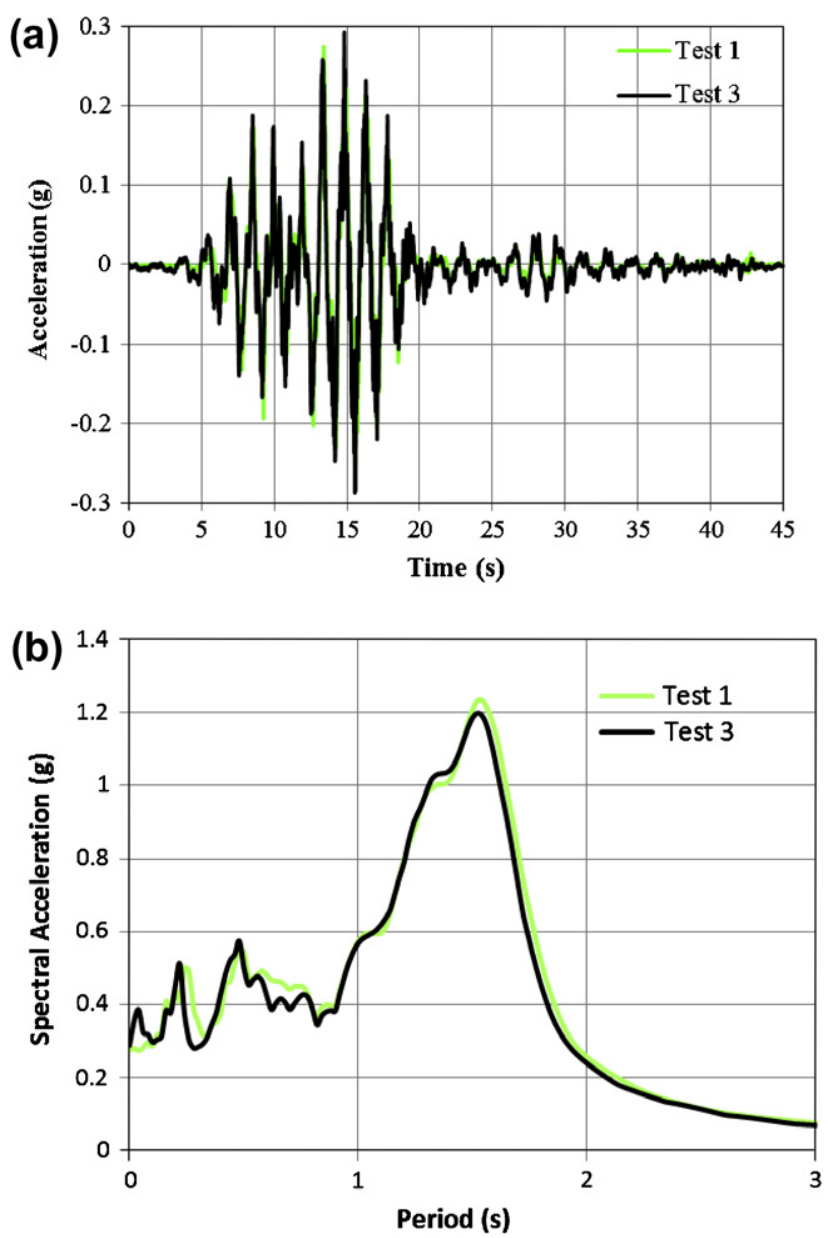

Fig. 1. (a) Input accelerations used in the centrifuge tests and numerical simulation and (b) response spectra of 5\% damping for the input motions.

included in the analysis domain. The saturated soil was discretized into two-phase bi-linear four node elements with four degrees of freedom (DOF) per node, two for solid phase and two for fluid phase kinematics. Finite element meshes used in the numerical simulation of centrifuge tests on homogeneous and heterogeneous soil together with the boundary conditions are shown in Fig. 2. Smaller finite elements were used below the structure, to more accurately capture the stress gradients. The finite element dimensions were controlled in such a way that the locations of each pore water pressure transducer coincided with the midpoint of an element, and accelerometer locations coincided with the node locations.

In the numerical model the structure was idealized as linearelastic. The material properties are shown in Table 1. The two strip footings were modeled using one-phase bi-linear four node elements with two degrees of freedom per node, for the solid phase kinematics. The beams and columns were discretized using 2-node beam elements with three degrees of freedom per node (two for displacements and one for rotation). The beams and roof masses were applied as nodal masses on the horizontal beam at the first floor level. The beams and columns dimensions and mass densities were modified to model them using the plane strain assumption. The fundamental period of the structure in prototype scale was $0.47 \mathrm{~s}$.

The walls of the centrifuge box were rigid; therefore, the rigid boundary was applied for the finite element mesh boundaries of the analysis domain. The input ground motion was applied in horizontal direction at the base and lateral boundary of the analysis domain, similar to the centrifuge experiment performed in a rigid 

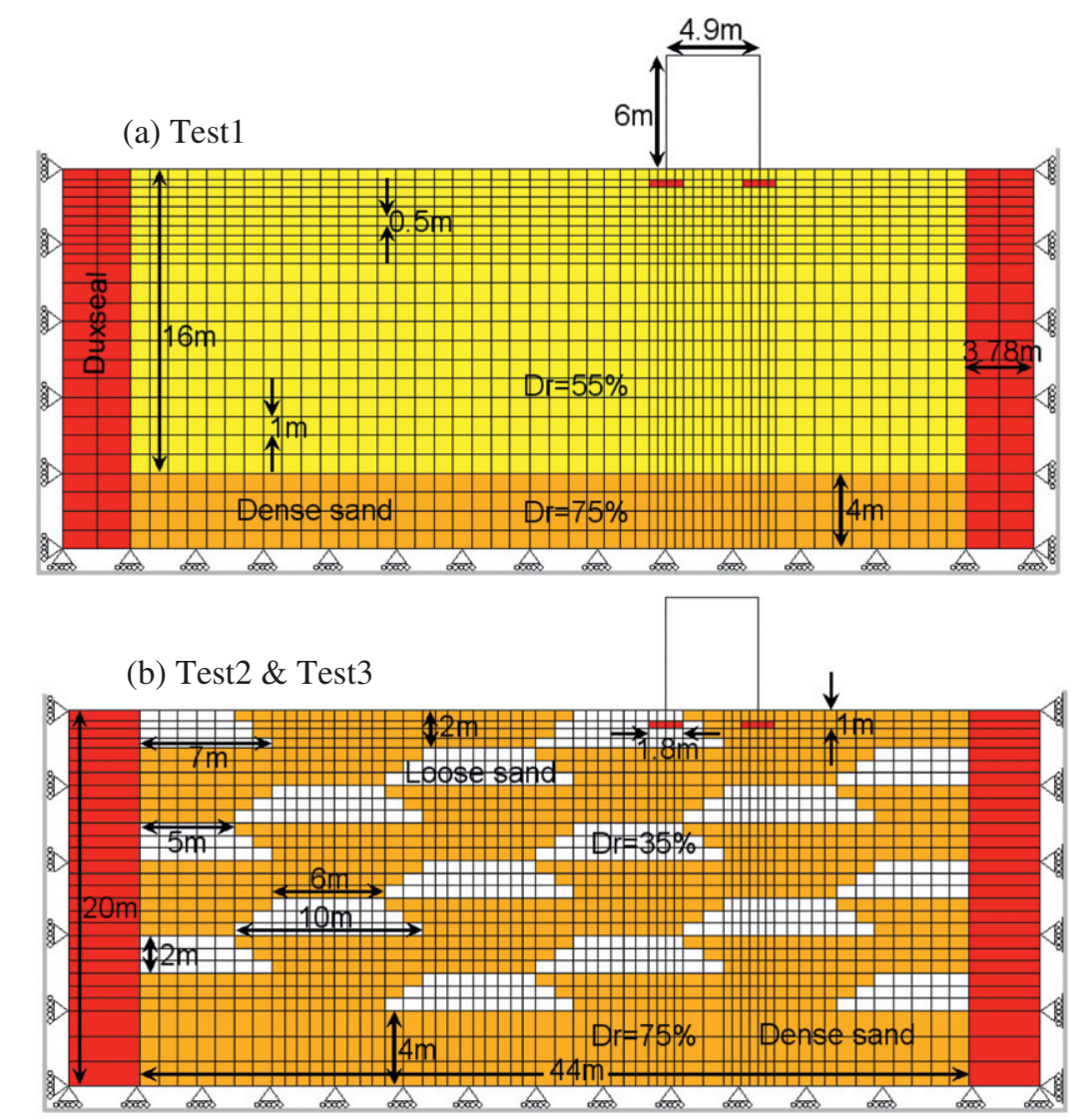

Fig. 2. Finite element meshes used in the numerical simulation of centrifuge tests on homogeneous and heterogeneous soil. The dimensions are in prototype scale.

Table 1

Constitutive parameters for linear-elastic materials used in the numerical simulation.

\begin{tabular}{lll}
\hline Constitutive parameter & Duxseal & Frame structures \\
\hline Mass density $\left(\mathrm{kg} / \mathrm{m}^{3}\right)$ & 1650 & 7813 \\
Young's modulus $(\mathrm{MPa})$ & 8 & 203,000 \\
Poisson's ratio & 0.46 & 0.287 \\
\hline
\end{tabular}

box. Use of a rigid box in earthquake simulation centrifuge experiments constrains the lateral shear deformations required for vertical propagating shear waves and induces a series of unwanted seismic waves that are generated by the reflection of seismic motion at each end wall of the box and are subsequently reflected back by the opposite wall. This phenomenon, which might induce a behavior in the model different from the real field, is partly attenuated by placing Duxseal (a relatively soft material) at each end wall of the box to create absorbing boundaries. Duxseal was used to treat the boundaries in the centrifuge experiments as suggested by [21], although the pros and cons for the use of Duxseal should be further investigated. This material was also considered in the numerical analyses, and idealized as linear-elastic. The material properties obtained from the literature (e.g., $[20,30]$ ) for Duxseal are listed in Table 1. Selective DOF slaving was used at the contact nodes to model the impervious surface between structure-soil, and soil-Duxseal.

\section{Numerical simulation of centrifuge tests: Homogeneous soil model}

The numerical analyses were performed to simulate the centrifuge tests on homogeneous and heterogeneous soil using fully coupled solid-fluid equations and a multi-yield surface plasticity soil constitutive model [32] implemented in DYNAFLOW [34]. The centrifuge models were subjected to an acceleration field 70 times higher than the gravity field. The stresses increased accordingly (high stresses at the base of the model and low stresses at the top) due to this higher gravity field which caused non-uniform stress densification in an initially uniform relative density model. The amount of stress densification was estimated based on a relation given by Park and Byrne [23].

\subsection{Soil constitutive model parameter estimation}

The parameters of the multi-yield plasticity model (used in this study) can be divided into state parameters (obtained from general laboratory soil tests), low-strain elastic parameters (describing elastic deformability), yield and failure parameters (used for generating the nested yield surfaces), and dilation parameters (used to calculate the plastic volumetric strain). All the multi-yield plasticity model parameters except the dilation parameter $\left(X_{p p}\right)$ can be estimated from results of conventional field (e.g., CPT, SPT) or laboratory soil tests. The dilation parameter, $X_{p p}$, is obtained by means of liquefaction strength analysis based on curve-fitting the experimental liquefaction strength curve using element tests (numerical simulations of undrained cyclic triaxial tests in this study).

Uthayakumar and Vaid [37] identified the Fraser River sand grains as sub-angular to sub-rounded. Castro [4] reported friction angle values for sub-rounded to sub-angular fine uniform sand with a relative density $30 \%$ in the range $31-34^{\circ}$ and for a relative density of $80 \%$ between $37.25^{\circ}$ and $41.25^{\circ}$. The range of friction angle at failure values reported in the literature for Fraser River sand is relatively scattered. As reported by Lunne et al. [19], the in situ friction angle of the Fraser River sand is in the range of 32-39 . 
The friction angle at failure, calculated from the results of the monotonic undrained triaxial tests performed on very loose ( $\mathrm{Dr}=20 \%$ ) Fraser River sand by Vaid et al. [41], is about $35^{\circ}$ in compression and $39^{\circ}$ in extension. A friction angle value of $37^{\circ}$ has been reported by Vaid and Eliadorani [38] for very loose Fraser River sand $(\mathrm{Dr}=11 \%)$. Based on all the above results, a range of friction angle at failure values of $37-43^{\circ}$ were selected in the analyses for $30-80 \%$ relative densities of the soil. Linear interpolation (as reported by [4]) was used for calculating friction angle for the intermediate values of relative densities.

From earlier research on Fraser River sand [42] and other sands [40] it has been observed that the value of the dilation angle (in DYNAFLOW), referred also as critical state angle and as phase transformation angle, does not depend upon the mode of loading, type of deformation or relative density. Based on laboratory tests performed under different conditions, a value of $34^{\circ}$ has been obtained for Fraser River sand by Vaid et al. [41]. Based on a series of undrained triaxial compression test on loose $(\mathrm{Dr}=11 \%)$ Fraser River sand specimen, Vaid and Eliadorani [38] obtained a phase transformation angle of about $32^{\circ}$. Uthayakumar and Vaid [37] reported a phase transformation angle value of $33^{\circ}$. The physical properties of the Fraser River sand used in this study are similar to the ones reported by Vaid et al. [41]. Therefore, a phase transformation angle of $34^{\circ}$ has been selected in this study for all relative densities.

In DYNAFLOW, the dependence of the low strain elastic shear $(G)$ and bulk moduli $(B)$ on the effective mean normal stress is taken as [34]:

$G=G_{0}\left(\frac{p}{p_{0}}\right)^{n}$ and, $B=B_{0}\left(\frac{p}{p_{0}}\right)^{n}$

where $p_{0}$ is a reference effective confining stress, $G_{0}$ and $B_{0}$ are the low strain shear and bulk modulus values corresponding to $p_{0}$, and $n$ is a power exponent. A typical value of $n=0.5$ was recommended by Richart et al. [35] for cohesionless soils.

In this numerical model, low strain shear modulus corresponds to the assumed range of soil deformation within the first yield surface. Two different symbols are used here for shear modulus: $G_{\max }$, shear modulus at very low strains $(0.0001-0.01 \%)$; and $G_{0}$, shear modulus at low strain $(0.05-0.1 \%)$. Based on the results from resonant column test or in situ shear wave velocity measurements, different correlations are derived by different researchers for calculating $G_{\max }$. The low strain shear modulus $\left(G_{0}\right)$ can be estimated for $0.05 \%$ strain level using modulus degradation curves and $G_{\max }$ values. Ishibashi and Zhang [13] suggested that $G_{\max }$ val- ues can be utilized in computations with a rather high degree of confidence when actual measurements are not available. For Fraser River sand at 30\% relative density, a value of shear modulus of about $28 \mathrm{MPa}$ at a shear strain of $0.05 \%$ was inferred from the results of isotropically consolidated triaxial tests performed by Vaid and Eliadorani [39]. This low strain shear modulus value was used for estimating $G_{0}$ at other relative densities by extrapolating the value for $30 \%$ relative density using following relation (based on [3]):

$\frac{G_{1}}{G_{2}}=\frac{e^{1.39 D_{r 1}}}{e^{1.39 D_{r 2}}}$

where $G_{1}$ is the low strain shear modulus at other relative density, $G_{2}$ is $28 \mathrm{MPa}, \mathrm{Dr}_{1}$ is the other relative density (e.g., $40 \%, 70 \%$, etc.) and $\mathrm{Dr}_{2}$ is $30 \%$ relative density.

For convenience in computer code implementation, Trautmann and Kulhawy [36] presented the following relation for Poisson's ratio:

$v=0.1+0.3 \varphi_{\text {rel }}$

where $\varphi_{\text {rel }}=\frac{(\varphi-25)}{(45-25)}=$ relative friction angle and its value is between 0 and 1 . The Poisson's ratio used in this study for different relative densities, were calculated using this relation.

The parameter $k_{0}$ is used by DYNAFLOW only for generating the deviatoric stress-strain backbone curves (e.g., [12]) and the initial locations of yield surfaces in the stress space [33]. Its value depends on the type of consolidation (e.g., anisotropic or isotropic) employed in the laboratory soil tests used for calibrating the model parameters. In this study the dilation parameter $\left(X_{p p}\right)$ is obtained based on the results from undrained triaxial tests done by Vaid et al. [41] on anisotropically consolidated $\left(k_{0}=0.8\right)$ Fraser River sand samples. The coefficient of lateral stress was taken as 0.8 in the study.

The maximum deviatoric strain is the strain required to reach the peak deviatoric stress. The maximum deviatoric strain in compression, estimated from the drained triaxial test results reported by Eliadorani [10] is about $10.67 \%$ for a Fraser River sample with a relative density of $27 \%$. Chillarige et al. [9] also documented drained triaxial test results on Fraser River sand, from which a very high (about 18\%) maximum deviatoric strain can be calculated for very loose samples. Therefore, based on those test results a maximum deviatoric strain of $10 \%$ in compression and $8 \%$ in extension are considered for $30 \%$ relative density. The maximum deviatoric strains estimated for the other relative densities are shown in Table 2.

Table 2

Parameters of the multi-yield plasticity model used for the saturated soil.

\begin{tabular}{|c|c|c|c|c|c|c|}
\hline \multirow[t]{2}{*}{ Type } & \multirow[t]{2}{*}{ Constitutive parameter } & \multirow[t]{2}{*}{ Symbol } & \multicolumn{3}{|l|}{ Relative density } & \multirow{2}{*}{$\begin{array}{l}\text { Relative density } \\
\text { (with stress densification) } \\
\text { Dr }=(33.6-75.05 \%)\end{array}$} \\
\hline & & & $\mathrm{Dr}=35 \%$ & $\mathrm{Dr}=55 \%$ & $\mathrm{Dr}=75 \%$ & \\
\hline \multirow[t]{3}{*}{ State parameters } & Mass density-solid & $\rho^{s}$ & $2710 \mathrm{~kg} / \mathrm{m}^{3}$ & $2710 \mathrm{~kg} / \mathrm{m}^{3}$ & $2710 \mathrm{~kg} / \mathrm{m}^{3}$ & $2710 \mathrm{~kg} / \mathrm{m}^{3}$ \\
\hline & Porosity & $n^{w}$ & 0.453 & 0.433 & 0.412 & $0.454-0.412$ \\
\hline & Hydraulic conductivity & $k$ & $0.008862 \mathrm{~cm} / \mathrm{s}$ & $0.00765 \mathrm{~cm} / \mathrm{s}$ & $0.00651 \mathrm{~cm} / \mathrm{s}$ & $0.00895 \mathrm{~cm} / \mathrm{s}-0.00651 \mathrm{~cm} / \mathrm{s}$ \\
\hline \multirow[t]{3}{*}{ Low strain elastic parameters } & Low strain elastic shear modulus & $G_{0}$ & $29.56 \mathrm{MPa}$ & $39.04 \mathrm{MPa}$ & $51.55 \mathrm{MPa}$ & 29.0 MPa-51.59 MPa \\
\hline & Poisson's ratio & $v$ & 0.289 & 0.325 & 0.361 & $0.286-0.361$ \\
\hline & Power exponent & $n$ & 0.5 & 0.5 & 0.5 & 0.5 \\
\hline \multirow[t]{4}{*}{ Yield and failure parameters } & Friction angle at failure & $\varphi$ & $37.6^{\circ}$ & $40^{\circ}$ & $42.5^{\circ}$ & $37.43-42.41^{\circ}$ \\
\hline & Maximum deviatoric strain (comp/ext) & $\varepsilon_{d e v}^{\max }$ & $9.6(C)$ & $8.0(C)$ & $6.4(C)$ & $9.7-6.4$ \\
\hline & & & $7.6(E)$ & $6.0(E)$ & $4.4(E)$ & $7.7-4.4$ \\
\hline & Coefficient of lateral stress & $k_{0}$ & 0.8 & 0.8 & 0.8 & 0.8 \\
\hline \multirow[t]{2}{*}{ Dilation parameters } & Dilation angle & $\psi$ & $34^{\circ}$ & $34^{\circ}$ & $34^{\circ}$ & $34^{\circ}$ \\
\hline & Dilation parameter & $X_{p p}$ & 0.074 & 0.031 & 0.0111 & $0.0777-0.0111$ \\
\hline
\end{tabular}


The coefficient of permeability is usually determined by performing constant and falling head permeability tests. Based on results of tests performed at UBC for 36 and $77 \%$ relative densities, the hydraulic conductivity values are calculated for other relative densities using the following relation (based on [8]):

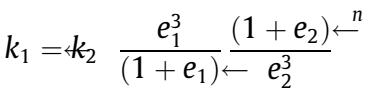

where $e_{1}, e_{2}$ are the void ratios corresponding to $k_{1}$ and $k_{2}$ and $n$ is calculated based on the coefficient of permeability results at 36 and $77 \%$ relative densities. All the estimated hydraulic conductivity values are modified next, to consider the effect of high viscosity fluid which was used in the centrifuge. This modification has been done using the fine tuning procedure of the multi-yield surface plasticity model parameters to best match the centrifuge experimental results in Test 1 (homogeneous soil).

After estimating all the other multi-yield plasticity parameters, the dilation parameter $\left(X_{p p}\right)$ was estimated next by performing a liquefaction strength analysis as described by Popescu and Prevost [26]. This analysis is based on fitting the experimental liquefaction strength curve using finite element simulations of cyclic undrained
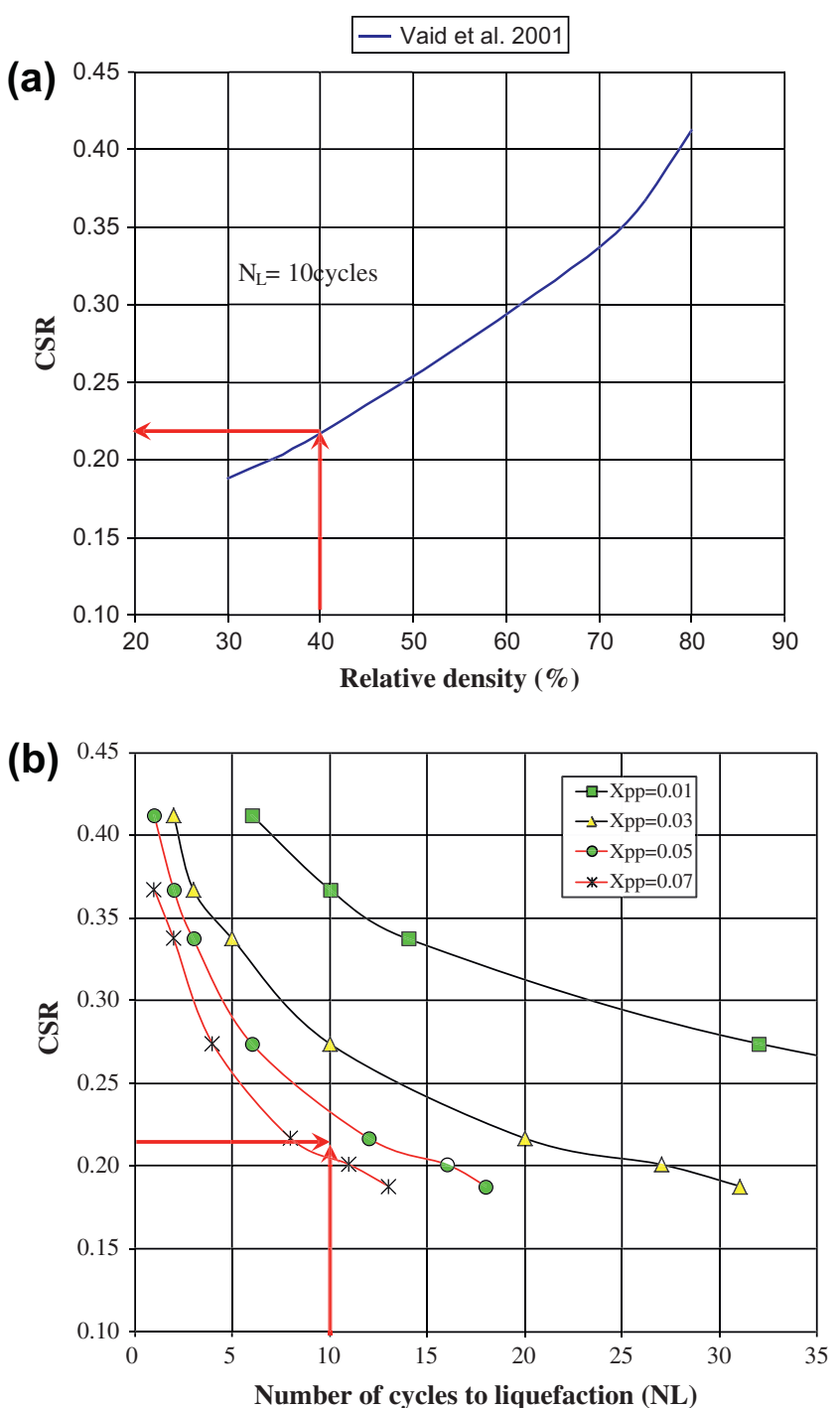

Fig. 3. Liquefaction strength analysis: (a) relation between soil relative density and cyclic stress ratio (CSR) which causes liquefaction in $N L=10$ cycle (obtained from [41]) and (b) illustrative example for calculating $X_{p p}$ from element test. An example for calculating $X_{p p}$ for $40 \%$ soil relative density is shown by arrows. triaxial tests (element tests). The dilation parameter $\left(X_{p p}\right)$ was obtained based on the results from undrained triaxial tests done by Vaid et al. [41] on anisotropically consolidated $\left(k_{0}=0.8\right)$ Fraser River sand samples. This liquefaction strength curve was selected because it gave a set of parameters which mimic the centrifuge test results on uniform soil deposits (Test 1 ) more accurately. The dilation parameter (shown in Table 2) was obtained based on the final number of cycles ( $N_{L}=10$ in this case) required for liquefaction. A typical example of calculating $X_{p p}$ from liquefaction strength curve and known soil relative density is shown in Fig. 3. Fig. 3a shows the available lab test results, corresponding to $N_{L}=10$ cycles, and Fig. $3 \mathrm{~b}$ shows the numerical liquefaction strength curves (LSCs) and how $X_{p p}$ was estimated based on available experimental data (namely one point on a LSC corresponding to $N_{L}=10$ cycles).

\subsection{Results and discussion}

The numerical simulation results, obtained using the fine-tuned multi-yield plasticity constitutive model parameters, are presented here with the results recorded in centrifuge tests. The recorded and computed EPWP ratios with respect to the initial vertical stress at four different locations in Test 1 (two locations below structure and two locations in the free field in homogeneous soil) are shown in Figs. 4 and 5. Except for a location very close to the structure (i.e., P2), the numerical model accurately predicted the results recorded in the centrifuge test. Settlements of the structure were also monitored during the tests. Recorded and computed settlements of the building in Test 1 are shown in Fig. 6 .

A comparison of acceleration time histories in Test 1 (homogeneous soil) recorded and computed at different depths in the free field are shown in Fig. 7. The recorded acceleration at $A 7$ shows very large high-frequency acceleration spikes during the strong ground motion. These spikes actually coincide with the negative pore pressure spikes during strong ground motion, and have been termed as de-liquefaction shock waves by Kutter and Wilson [18]. However, the numerical model was not able to reproduce those dilation spikes recorded during centrifuge tests.

\section{Numerical simulation of centrifuge tests: Heterogeneous soil model}

There are sixteen loose pockets at eight different depths inside the heterogeneous soil. In each horizontal layer, the loose pockets were deposited first. Then, the remaining spaces were filled with dense sand. Two light weight trapezoidal blocks were used for constructing loose pockets during sand raining. The new relative densities after stress densification (because of higher gravitational field in centrifuge) were verified during centrifuge tests by measuring the volume of soil in the box before the test and after the first spin. The average soil density of the model was also calculated. The estimated relative densities (after stress densification) were considered in the numerical simulations of heterogeneous soil deposit model. The preparation of loose pockets in heterogeneous soil, instrumentation, measurements and verification of the density in heterogeneous soil model is presented in more details by Chakrabortty et al. [6]. The next step of this study was comparing the numerical simulation results (using the fine-tuned soil parameters) and the experimental results for heterogeneous soil (Test 3 ). The comparison results are presented in Figs. 8-12. The recorded and computed EPWP ratios with respect to the initial vertical stress at four different locations in the free field in Test 3 (on heterogeneous soil) are shown in Fig. 8. Comparisons of recorded and computed EPWP ratios below the structure in heterogeneous soil are shown in Fig. 9. From the results on the heterogeneous soil model it was observed that the numerical simulation results were in 

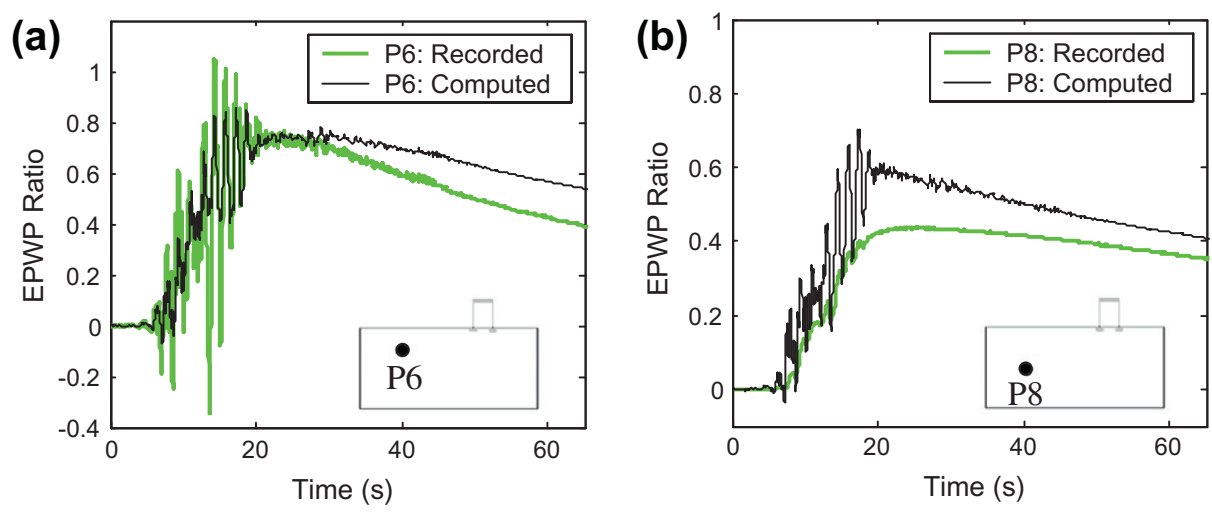

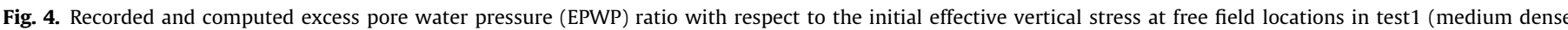
homogeneous soil): (a) at shallow depth: P6 and (b) at larger depth: P8.
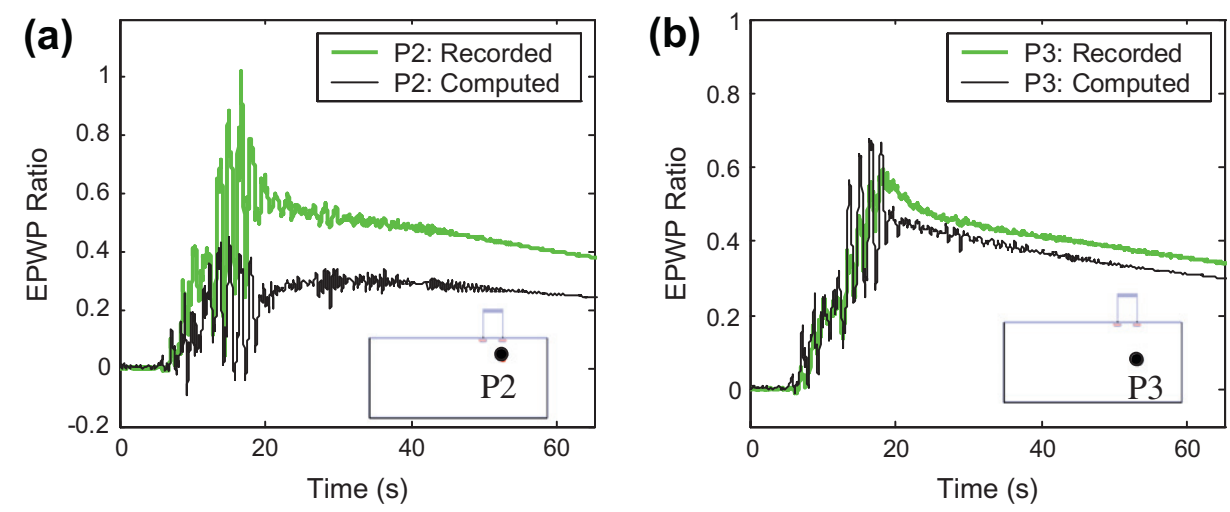

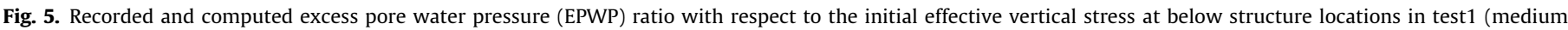
dense homogeneous soil): (a) at shallow depth: P2 and (b) at larger depth: P3.
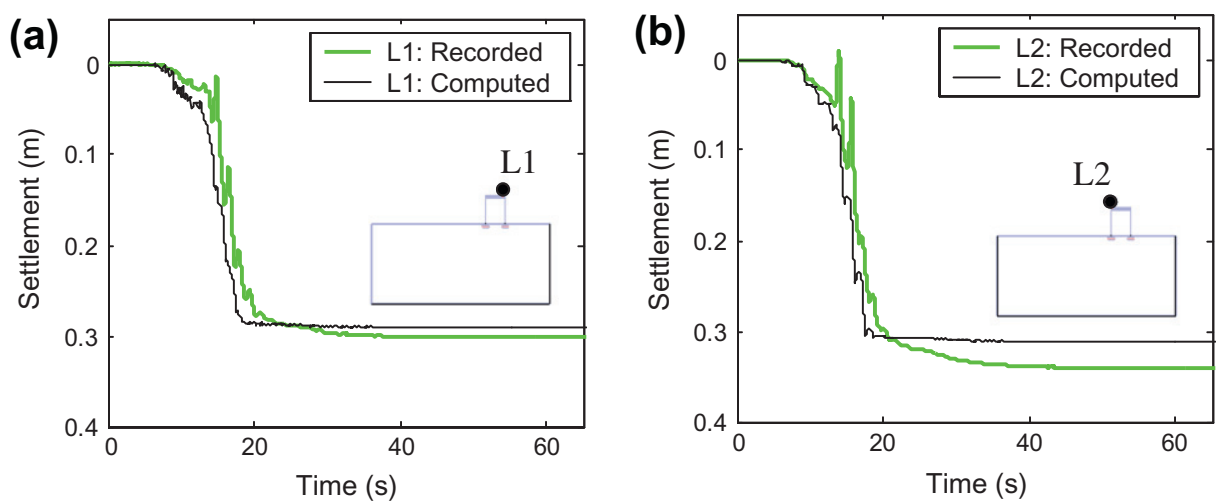

Fig. 6. Recorded and computed settlement of building in test1 (homogeneous soil): (a) L1 and (b) L2.

agreement with the experimental results (again, excepting location P2). The numerical model predicted more dilative behavior for the soil at P2 than that observed in the centrifuge tests. This is believed to be due to a limitation of the constitutive model that predicts excessive dilation in the presence of static shear. However, the numerical model was deemed sufficiently accurate for the purpose of this study.

Fig. 10a and $\mathrm{b}$ shows the comparison of the EPWP ratio between homogeneous and heterogeneous soil, recorded after the end of earthquake ground motion during centrifuge tests. This experimental results consistently indicate a larger EPWP build-up in heterogeneous soil than in homogeneous soil (e.g., at $5 \mathrm{~m}$ depth in the free field, the EPWP ratio in heterogeneous soil is 1 whereas in homogeneous soil it is 0.7). A comparison between recorded EPWP ratio time histories recorded at the same location in the two centrifuge tests with different soils is shown for transducer P3 in Figs. 5b and 9c. Fig. 5b shows the recorded EPWP ratio in medium dense sand in the homogeneous soil deposit. Fig. 9c shows the recorded EPWP ratio in the dense sand matrix in the heterogeneous soil deposit. It is clear from these results that more EPWP is generated in dense sand in the heterogeneous soil than in medium dense sand in the homogeneous soil. This difference is more evident toward the end of analysis time (after the earthquake) when the dense sand matrix drains slower than the medium dense sand, 


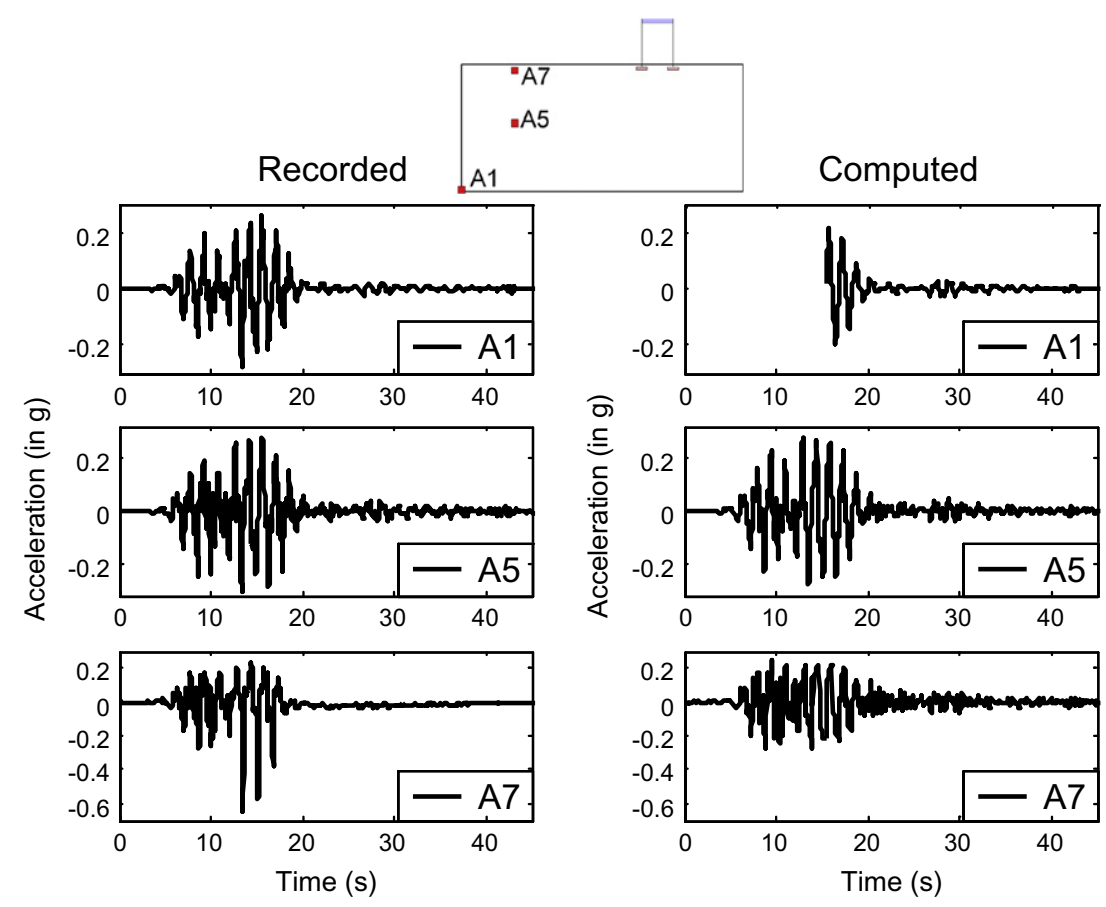

Fig. 7. Recorded and computed accelerations in test1 (homogeneous soil).
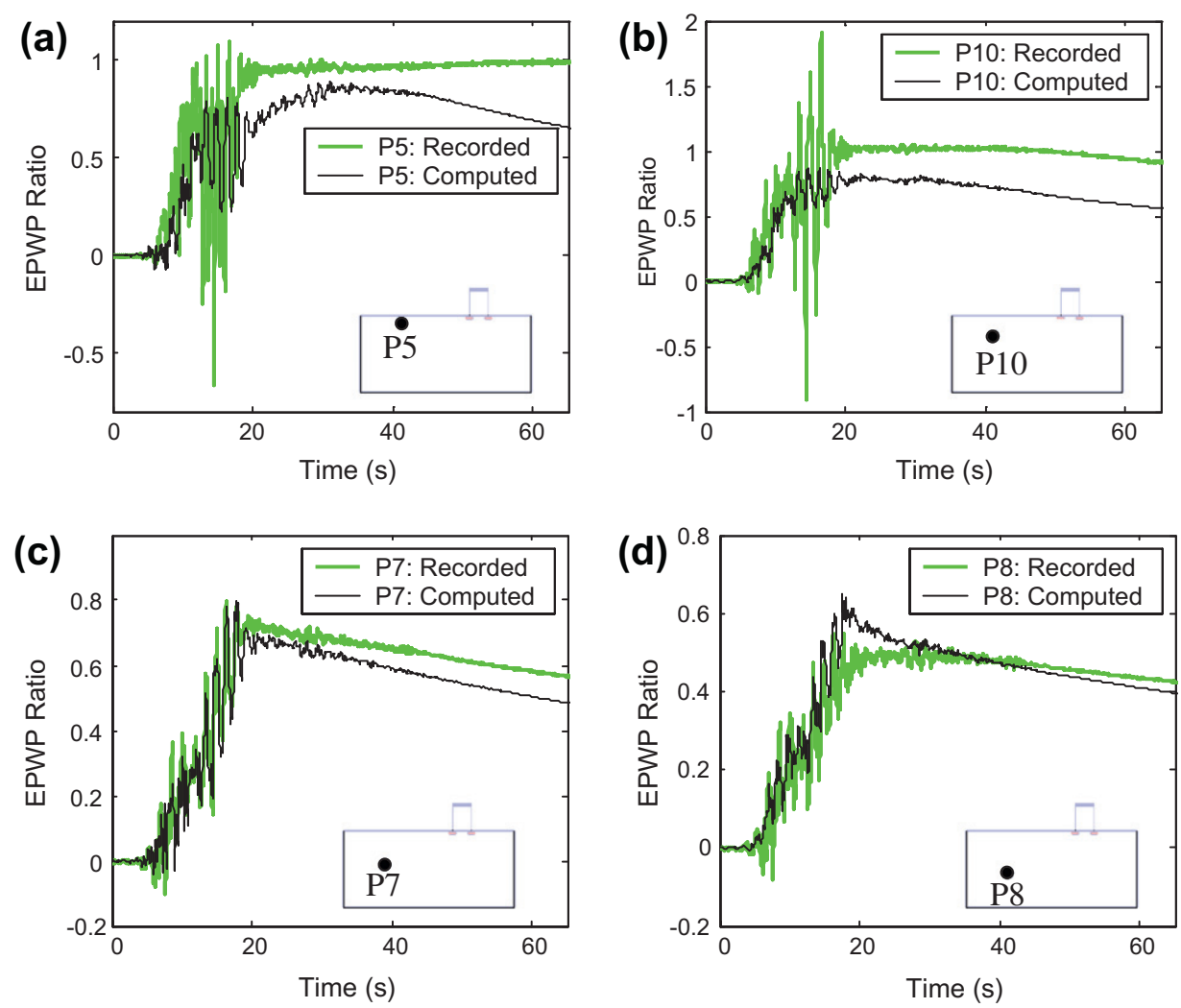

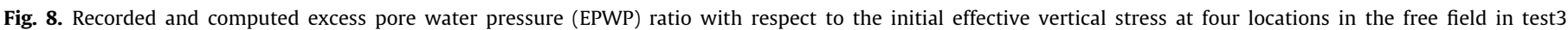
(heterogeneous soil): (a) P5: dense sand; (b) P10: loose sand; (c) P7: dense sand; (d) P8: loose sand.

apparently due to pore water fed from neighboring loose zones. Overall, the experimental results obtained here show more excess pore water pressure is generated in the heterogeneous soil than in the homogeneous soil, even when the average relative density of the heterogeneous soil $(\mathrm{Dr}=64 \%)$ is larger than the relative density of the homogeneous soil $(\mathrm{Dr}=55 \%)$. Liquefaction resistance is 

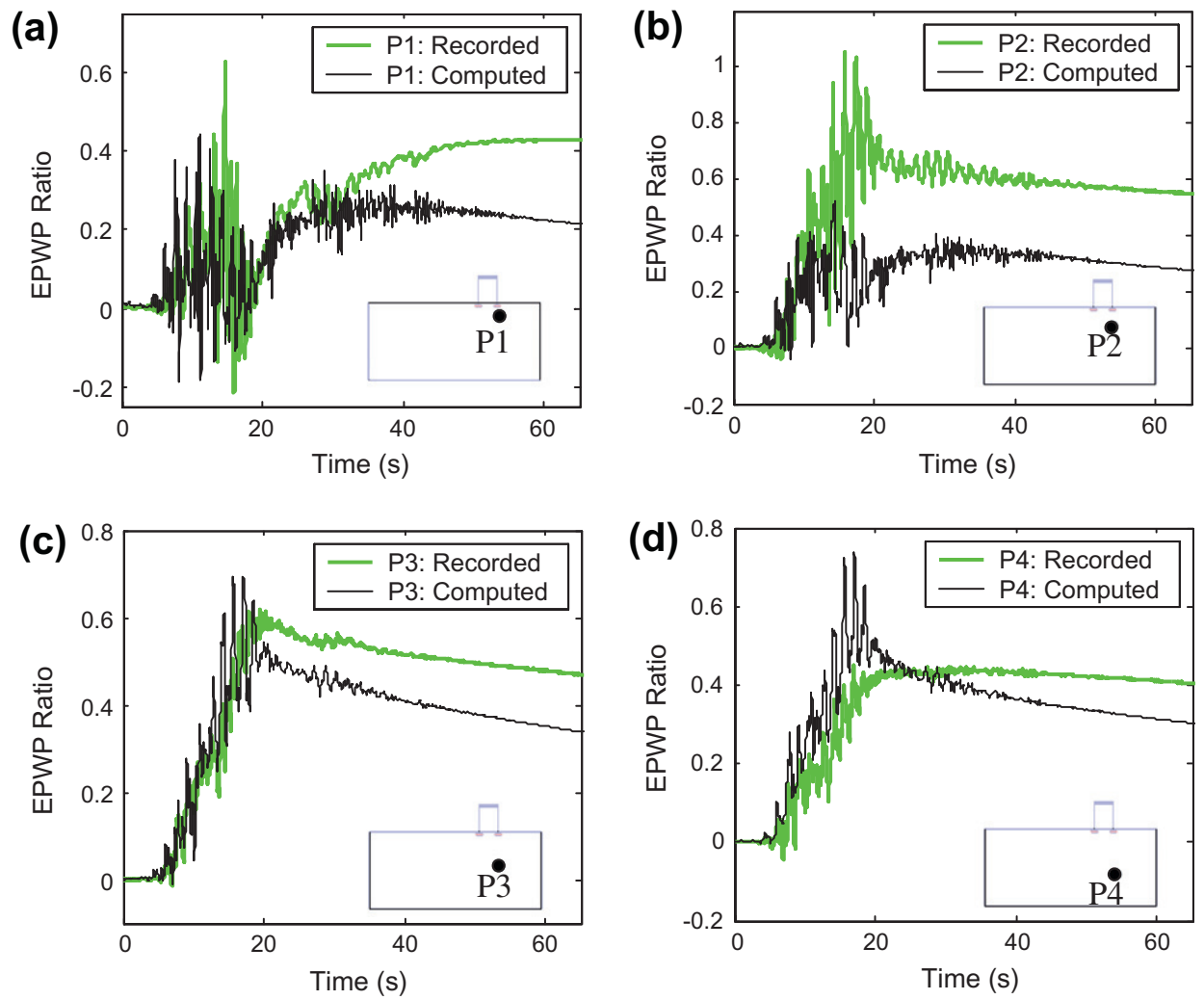

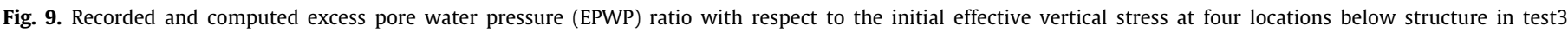
(heterogeneous soil): (a) P1: dense sand; (b) P2: loose sand; (c) P3: dense sand; (d) P4: loose sand.

(a)

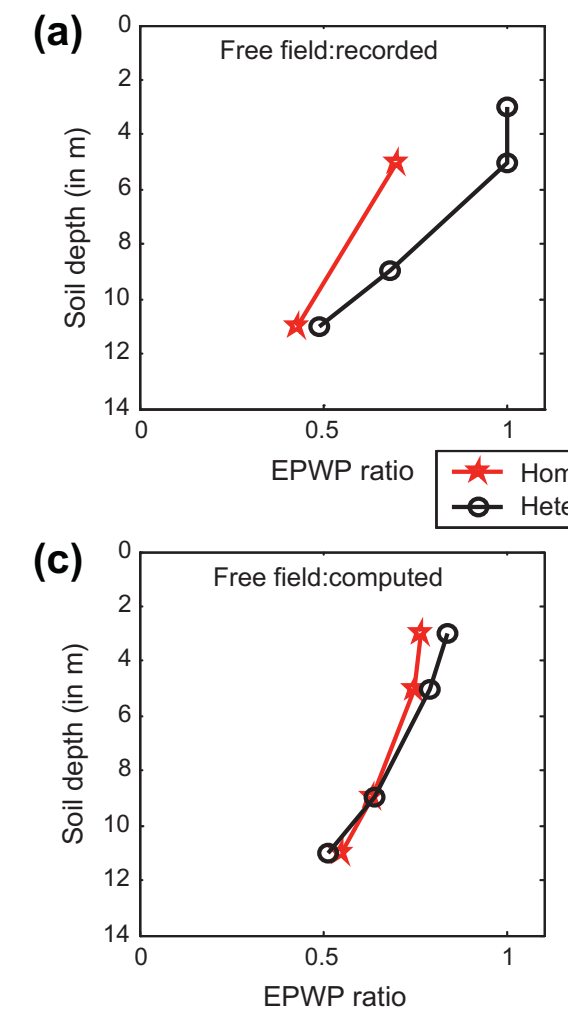

(b)

(b)

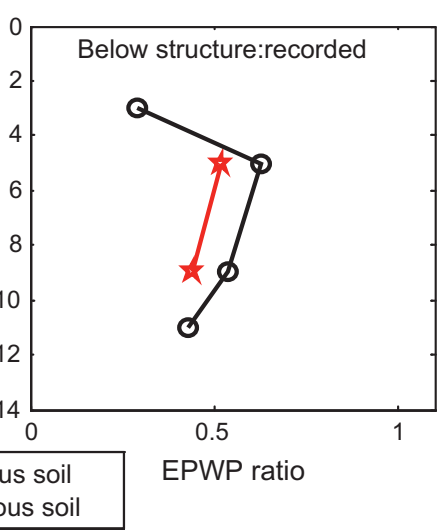

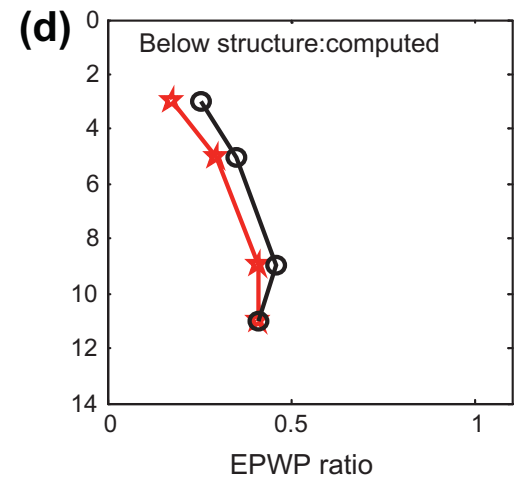

Fig. 10. Comparison of excess pore water pressure (EPWP) ratio between homogeneous and heterogeneous soil at time $t=30 \mathrm{~s}($ depths at prototype scale). 

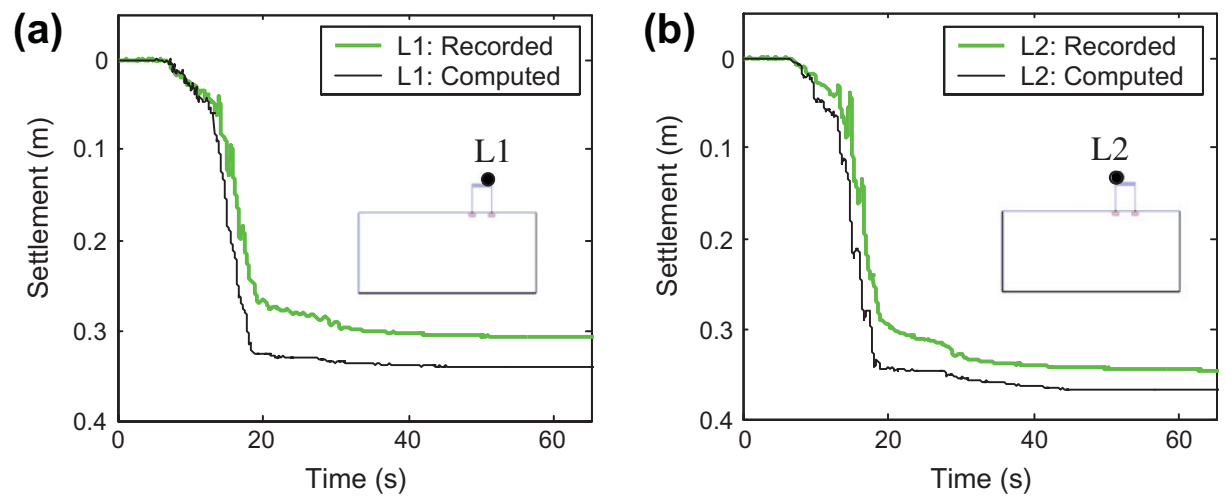

Fig. 11. Recorded and computed settlement of building in test3 (heterogeneous soil): (a) L1 and (b) L2.

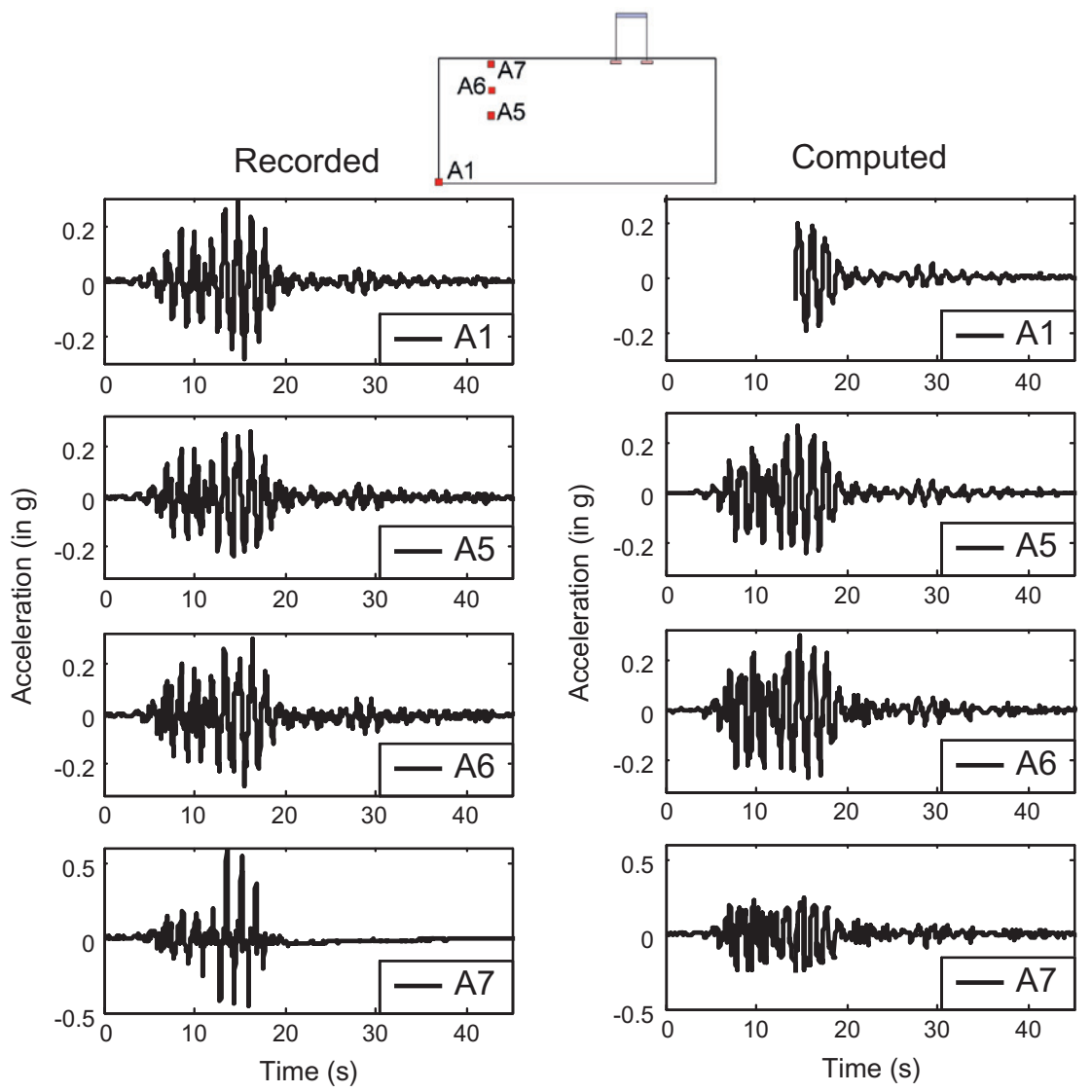

Fig. 12. Recorded and computed accelerations in test3 (heterogeneous soil).

assessed here in relation to the pore pressure ratio. Similar results have also been reported for layered soil and localized loose patch [11] and in cyclic triaxial tests with layered soil samples [16].

Similar results, obtained from numerical simulation of the centrifuge tests, are shown in Fig. 10c and d. Although the heterogeneous soil deposit was on average denser than the uniform soil, more EPWP was generated than in the uniform soil. Similar conclusions were also observed from earlier numerical simulations of heterogeneous soil (e.g., [24]).

Comparisons between numerical and experimental results for structure settlements in Test 3 (heterogeneous soil) are shown in Fig. 11. Results in terms of settlements do not show any significant difference between homogeneous and heterogeneous soil (both numerical and experimental). Computed and recorded acceleration time histories in the heterogeneous soil model are shown in Fig. 12. Arias intensities of acceleration records at locations A5 and A7 were compared between homogeneous soil and heterogeneous soil. Detailed results of this comparison are presented in Ref. [6]. In summary, it resulted that the Arias intensities of acceleration records in homogeneous soil are significantly larger than those in heterogeneous soil, by $34 \%$ at transducer A5 and by $23 \%$ at transducer A7. As Arias intensity is a measure of energy delivered per unit mass of soil during the earthquake, this difference indicates larger attenuation of seismic waves in the heterogeneous soil deposit than in the homogeneous soil deposit. From this result it appears that, although the heterogeneous soil deposit was on 
average denser than the homogeneous soil, seismic wave amplification was lower in the heterogeneous soil due to higher excess pore water pressure build-up.

\section{Conclusions}

The liquefaction in homogeneous and heterogeneous soil deposit is explained in detail using the numerical simulation of centrifuge tests. Based on a detailed analysis of numerical results, this study provides an explanation for an interesting and important behavior detected in previous theoretical work, namely that more excess pore water pressure is generated by seismic loads in a heterogeneous soil than in an equivalent uniform soil. This behavior was observed in this study even when using a heterogeneous soil deposit of average relative density $\left(\mathrm{Dr}^{\mathrm{av}}=64 \%\right)$ higher than the relative density of the uniform soil deposit $(\mathrm{Dr}=55 \%)$. The explanation of this phenomenon is water migration from loose to dense soil zones in heterogeneous soil deposits. The end result is excess pore water pressure build-up (and therefore temporary reduction of shear strength) in dense sands, in the vicinity of loose soil pockets. Settlements recorded in the structure do not show any adverse effect of soil heterogeneity for the soil property variability considered in the experiments. Further investigation is needed regarding this aspect.

Finally, it should be mentioned that the heterogeneous soil deposits exemplified here exhibit large, sudden variations in relative density from one location to another, unlike natural soil deposits where those variations are gradual. Therefore, the results of this study may over-emphasize the effects of soil heterogeneity on water migration in spatially variable soils. However, as most laboratory soil testing procedures use uniform soil samples for assessing the liquefaction potential, their results in terms of cyclic induced excess pore pressures may well be on the under-conservative side when applied to natural soil deposits exhibiting inherent spatial variability of their properties. It is mentioned that liquefaction assessment methods based on comparisons between normalized penetration test results (e.g., SPT, CPT) and observed field performance (see e.g., [43]) are not affected, as the effects of natural soil heterogeneity are captured by these methods.

\section{Acknowledgments}

The financial support provided by NSERC under Research Grant No. RG203795-06 is gratefully acknowledged. The authors are also indebted to C-CORE Centrifuge Centre staff for their help during centrifuge tests.

\section{References}

[1] Arulanandan K, Scott RF, editors. International conference on verification of numerical procedures for the analysis of soil liquefaction problems, vol. 1. Rotterdam: Balkema; 1993;

Arulanandan K, Scott RF, editors. International conference on verification of numerical procedures for the analysis of soil liquefaction problems. vol. 2. Rotterdam: Balkema; 1994.

[2] Arulmoli K, Muraleetharan KK, Hossain MM, Fruth LS. Verification of liquefaction analysis by centrifuge studies (VELACS) laboratory testing program soil data report. National Science Foundation (NSF), Earth Technology project No. 90-0562; March 1992.

[3] Belloti R, Ghionna V, Jamiolkowski M, Lancellotta R, Manfredini G. Deformation characteristics of cohesionless soils from in-situ tests. In: Use of in-situ tests in geotechnical engineering. Clemence SP, (editor); 1986. p. 47-73.

[4] Castro G. Liquefaction of sands. Ph.D. thesis, Harvard University, Cambridge; 1969.

[5] Chakrabortty P. Seismic liquefaction of heterogeneous soil: mechanism and effects on structural response. PhD thesis, Memorial University of Newfoundland; 2008.

[6] Chakrabortty P, Popescu R, Phillips R. Liquefaction of heterogeneous sand: centrifuge study. ASTM Geotech. Test. J. (GTJ) 2010;33(4):227-37.
[7] Chakrabortty P, Popescu R, Phillips R, Dief H. Liquefaction of heterogeneous soil: centrifuge study. In: 12th International conference of international association for computer methods and advances in geomechanics (IACMAG), Goa, India; October 1-6, 2008.

[8] Chapuis RP. Predicting the saturated hydraulic conductivity of sand and gravel using effective diameter and void ratio. Can Geotech J 2004;41(5):787-95.

[9] Chillarige AV, Robertson PK, Morgenstern NR, Christian HA. Evaluation of the in situ state of Fraser River sand. Can Geotech J 1997;34:510-9.

[10] Eliadorani A. The effect of drainage conditions on liquefaction response of sands. In: 54th Canadian geotechnical conference, Calgary, Alberta, Canada; September 2001.

[11] Ghosh B, Madabhushi SPG. Effects of localized soil inhomogeneity in modifying seismic soil-structure interaction. In: 16th ASCE engineering mechanics conference, Seattle, WA; July 2003.

[12] Griffiths DV, Prevost JH. Stress strain curve generation from simple triaxial parameters. Int J Numer Anal Methods Geomech 1990;14:587-94.

[13] Ishibashi I, Zhang X. Unified dynamic shear moduli and damping ratios of sand and clay. Soils Found 1993;33(1):182-91.

[14] Jafari-Mehrabadi A. Seismic liquefaction countermeasures for waterfront slopes. PhD thesis, Memorial University of Newfoundland; 2006.

[15] Keanne CM, Prevost JH. An analysis of earthquake data observed at the Wildlife liquefaction array site, Imperial County, California. In: 2nd US-Japan workshop on liquefaction, large ground deformations and effects on lifelines, New York; 1989. p. 39-53.

[16] Konrad JM, Dubeau S. Cyclic strength of stratified soil samples. In: Proc 55th Canadian geotechnical conference: ground and water: theory to practice Niagara Falls, ON; October 2002. p. 89-94.

[17] Krsteji I, Prévost JH. VELACS Class A centrifuge model test 12. Technical report Princeton University; 1993.

[18] Kutter BL, Wilson DW. De-liquefaction shock waves. In: Proc 7th US Japan workshop on earthquake resistant design of life line facilities and countermeasures against liquefaction; 1999. p. 295-310.

[19] Lunne T, Robertson PK, Powell J. Cone penetration testing in geotechnical practice. Blackie Academic and Professional; 1997.

[20] Madabhushi SPG, Schofield AN. Centrifuge modeling of tower structures on saturated sands subjected to earthquake perturbations. Geotechnique 1993:43(4):555-65.

[21] Madabhushi SPG, Schofield AN, Zeng X. Complementary shear stresses in dynamic centrifuge modelling, dynamic geotechnical testing II, ASTM STP 1213. American society for testing and materials; 1993 . p. 346-59.

[22] National Building Code of Canada (NBCC). Canadian commission on building and fire codes. National research council of Canada, Ottawa; 2005.

[23] Park SS, Byrne PM. Stress densification and its evaluation. Can Geotech J 2004;41(1):181-6.

[24] Popescu R, Chakrabortty P. Liquefaction mechanism for heterogeneous soils Sea to sky geotechnique. In: 59th Canadian geotechnical conference and 7th joint CGS/IAH-CNC groundwater specialty conference. BC, Canada: Vancouver; October 1-4, 2006.

[25] Popescu R, Chakrabortty P, Prévost JH. Fragility curves for tall structure on stochastically variable soil. In: 9th International conference on structural safety and reliability (ICOSSAR), Rome, June; 2005a.

[26] Popescu R, Prevost JH. Centrifuge validation of a numerical model for dynamic soil liquefaction. Soil Dyn Earthquake Eng 1993;12(2):73-90.

[27] Popescu R, Prévost JH. Comparison between VELACS numerical "Class A" predictions and centrifuge experimental soil test results. Soil Dyn Earthquake Eng 1995;14(2):79-92.

[28] Popescu R, Prévost JH, Deodatis G. Effects of spatial variability on soil liquefaction: some design recommendations. Geotechnique 1997;47(5):1019-36.

[29] Popescu R, Prévost JH, Deodatis G. 3D effects in seismic liquefaction of stochastically variable soil deposits. Geotechnique 2005;55(1):21-31.

[30] Popescu R, Prévost JH, Deodatis G, Chakrabortty P. Dynamics of nonlinear porous media with applications to soil liquefaction. J Soil Dyn Earthquake Eng 2006;26(6-7):648-65.

[31] Prevost JH. A simple plasticity theory for frictional cohesionless soils. Soil Dyn Earthquake Eng 1985;4(1):9-17.

[32] Prévost JH. Wave propagation in fluid-saturated porous media: an efficient finite element procedure. Soil Dyn Earthquake Eng 1985;4(4):183-202.

[33] Prevost JH. DYNA1D a computer program for nonlinear seismic site response analysis. Technical documentation NCEER-89-0025. Technical report, Department of Civil Engineering and Operational Research, Princeton University; 1989.

[34] Prévost JH. DYNAFLOW - a nonlinear transient finite element analysis program. Version 02. Technical report, Department of Civil and Environmental Engineering, Princeton University, Princeton, NJ; 2002. $<$ http://www.princeton.edu/ dynaflow>.

[35] Richart Jr FE, Hall Jr JR, Woods RD. Vibrations of soils and foundations. Englewood Cliffs: Prentice Hall; 1970.

[36] Trautmann CH, Kulhawy FH. CUFAD - a computer program for compression and uplift foundation analysis and design. Report EL-4540-CCM, vol. 16. Electric Power Research Institute, Palo Alto; 1987 October.

[37] Uthayakumar M, Vaid YP. Static liquefaction of sands under multiaxial loading. Can Geotech J 1998;35(2):273-83.

[38] Vaid YP, Eliadorani A. Instability and liquefaction of granular soils under undrained and partially drained states. Can Geotech J 1998;35(6):1053-62. 
[39] Vaid YP, Eliadorani A. Undrained and drained (?) stress-strain response. Can Geotech J 2000;37(5):1126-30.

[40] Vaid YP, Chern JC. Cyclic and monotonic undrained response of saturated sands, advances in the testing soils under cyclic condition. ASCE 1985;1:120-47.

[41] Vaid YP, Stedman JD, Sivathayalan S. Confining stress and static shear effects in cyclic liquefaction. Can Geotech J 2001;38(3):580-91.
[42] Vaid YP, Thomas J. Liquefaction and post liquefaction behaviour of sand. J Geotech Eng ASCE 1995;121:163-73.

[43] LYoud TL, Idriss IM, Andrus RD, Arango I, Castro G, Christian JT, et al. Liquefaction resistance of soils: summary report from the 1996 NCEER and 1998 NCEER/NSF workshops on evaluation of liquefaction resistance of soils. J Geotech Eng Geo-environ Eng ASCE 2001;127(10):817-33. 